\title{
Perfil fermentativo de silagens de cana-de-açúcar in natura ou queimada e tratadas ou não com Lactobacillus buchneri ${ }^{1}$
}

\section{Gustavo Rezende Siqueira 2,3 , Ricardo Andrade Reis $3,4,5$, Ruben Pablo Schocken-Iturrino ${ }^{3,4}$, Anna Paula de Toledo Piza Roth ${ }^{3}$, Marcella de Toledo Piza Roth ${ }^{3}$, Flávio Dutra de Resende ${ }^{2,3,4}$}

\author{
1 Projeto financiado pela FAPESP processo 04/14352-7. \\ ${ }^{2}$ Apta - Pólo Regional da Alta Mogiana - Av. Rui Barbosa, s/nº, C.P. 35, 14770-000, Colina - SP \\ ${ }^{3}$ Faculdade de Ciências Agrárias e Veterinárias - Unesp - Campus de Jaboticabal - SP. \\ ${ }^{4}$ Bolsista de produtividade do CNPq. \\ ${ }^{5}$ Membro do INCT-CA.
}

RESUMO - Objetivou-se comparar as perdas, a dinâmica microbiológica e as alterações fermentativas e nutritivas de silagens de cana-de-açúcar in natura ou queimada e tratadas ou não com Lactobacillus buchneri durante o período de armazenamento. Os tratamentos foram cana-de-açúcar in natura ou tratada com L. buchneri e cana-de-açúcar queimada ou tratada com L. buchneri, avaliadas com $0,1,4,7,14,28$ e 56 dias de fermentação, em três repetições por tratamento. Apenas antes da ensilagem foi constatada diferença significativa na população de leveduras entre cana-de-açúcar in natura e queimada, cujos valores foram de 4,85 e 5,43 log ufc/g de forragem, respectivamente. No decorrer do tempo de fermentação, ocorreu redução da recuperação de matéria seca e as perdas se prolongaram até o dia 56. A concentração de etanol foi alta até o dia 28 e estável até o dia 56, sem diferença entre tratamentos. A digestibilidade verdadeira in vitro da matéria seca sofreu severa redução já no primeiro dia de armazenamento, chegando a reduzir cerca de 20 unidades percentuais aos 56 dias de armazenamento. Silagens de cana-de-açúcar queimada apresentam maiores perdas e alterações fermentativas e nutricionais que silagens de cana-de-açúcar in natura. O L. buchneri deve ser utilizado em silagens de cana-de-açúcar queimada, mas nas de cana-de-açúcar in natura seu uso é dispensável.

Palavras-chave: ensilagem, fermentação, inoculante bacteriano, L. buchneri, leveduras

\section{Fermentative profile of silage of fresh or burned sugarcane treated or not with L. buchneri}

\begin{abstract}
The objective of this work was to compare losses, microbiological dynamics and nutritional and fermentative alterations in silages of fresh or burned sugar cane treated or not with Lactobacillus buchneri during storage period. Treatments were fresh sugar cane or treated with $L$. buchneri and sugar cane burned or treated with $L$. buchneri, evaluated with $0,1,4,7,14,28$ and 56 days of fermentation, in three replicates per treatment. Only before ensiling it was observed significant difference in the yeast population between fresh and burned sugar cane, whose values were 4.85 and $5.43 \mathrm{log} \mathrm{ufc} / \mathrm{g}$ of forage, respectively. Over fermentation time, it occurred reduction of dry matter recovery and losses lasted until the $56^{\text {th }}$ day. Ethanol concentration was high until day 28 and steady until day 56, with no difference among treatments. In vitro true dry matter digestibility was severely reduced in the first days of storage, reducing approximately 20 percentage units at 56 days of storage. Silage from burned sugar cane showed the greatest losses and changes on the fermentative and nutritional traits compared to fresh sugar cane silage. L. buchneri should be used on the burned sugar cane silage but for fresh sugar cane silage, its use is not necessary.
\end{abstract}

Key Words: bacterial inoculants, ensilage, fermentation, L. buchneri, yeast

\section{Introdução}

Em confinamentos, a cana-de-açúcar é um dos volumosos mais utilizados na alimentação de ruminantes, devido à alta produtividade de energia por área. Todavia, o risco de incêndios acidentais pode comprometer o uso da cana-de-açúcar fresca. Neste caso, a ensilagem poderia ser utilizada não somente como prevenção, mas também como solução. Em estudo pioneiro sobre os efeitos do fogo na ensilagem da cana-de-açúcar, Bernardes et al. (2007) constataram que silagens de cana-de-açúcar queimada apresentam maiores concentrações de etanol (7,3 versus 
6,5\%) e maiores populações de leveduras (2,7 versus 2,2 log ufc/g de silagem) em comparação a silagens de cana-deaçúcar in natura.

Segundo Siqueira et al. (2007a), o principal microrganismo responsável pelas perdas durante a fermentação de cana-de-açúcar são as leveduras, que, em anaerobiose, fermentam carboidratos solúveis e produzem $\mathrm{CO}_{2}$ e etanol, gerando perdas de até 48,9\% da MS (McDonald et al., 1991). Vários aditivos têm sido utilizados com intuito de reduzir as perdas no processo fermentativo, entre eles, benzoato de sódio, ureia e a bactéria heterofermentativa Lactobacillus buchneri (Nussio \& Schmidt, 2004). Todavia, autores alertam para a necessidade de novas pesquisas com esses e com novos aditivos.

Este trabalho foi realizado com o objetivo de comparar as perdas, a dinâmica microbiológica e as alterações fermentativas e nutritivas de silagens de cana-de-açúcar in natura ou queimada tratadas ou não com Lactobacillus buchneri durante a fermentação.

\section{Material e Métodos}

A cana-de-açúcar (Saccharum officinarum L.) utilizada foi a variedade IAC 86-2480, produzida no Pólo Regional de Desenvolvimento dos Agronegócios da Alta Mogiana Apta Regional de Colina. A colheita mecânica foi realizada em setembro de 2006, quando a cana-de-açúcar apresentava-se apta para o corte, com produção de $130 \mathrm{t}$ MV/ha aos 18 meses de crescimento vegetativo - cana planta.

Nos tratamentos de cana-de-açúcar queimada, a queima foi realizada no final da tarde do dia anterior ao corte para ensilagem. As canas-de-açúcar in natura e queimada foram colhidas com ensiladora modelo Menta Mit 3000 em partículas de 1 a $3 \mathrm{~cm}$.

Os tratamentos consistiram da utilização ou não do Lactobacillus buchneri (LB), na cana-de-açúcar in natura ou queimada, avaliados em diferentes tempos de armazenamento. O delineamento experimental utilizado foi inteiramente casualizado, em esquema fatorial $(2 \times 2 \times 7)$ sendo o primeiro fator o manejo (cana-de-açúcar in natura ou queimada), o segundo o inoculante (sem ou com LB) e o terceiro os tempos de armazenamento $(0,1,4,7,14,28$ e 56 dias) com três repetições por tratamento.

O inoculante bacteriano utilizado foi composto pelo microrganismo Lactobacillus buchneri (Cepa NCIMB 40788), da empresa Lallemand Animal Nutrition, e a dose utilizada foi de $5 \times 10^{4} \mathrm{ufc/g}$ de massa ensilada. O produto foi aplicado diluído em água, na razão de 100 g em 50 L de água e aplicado na dose de $2 \mathrm{~L}$ por tonelada de massa ensilada.
Como silos experimentais foram utilizados baldes de plástico com capacidade de $7 \mathrm{~L}$, munidos de tampas com válvulas de Bunsen para permitir o escape dos gases. No fundo dos silos, foram colocados $2 \mathrm{~kg}$ de areia seca, separada da forragem por uma tela e um tecido de náilon, para quantificação do efluente produzido. Para determinação da massa específica, foi determinado o volume de cada silo experimental, descontando-se o espaço ocupado pela areia e pesou-se a quantidade de forragem acondicionada em cada silo. Nas silagens de cana-de-açúcar in natura, a massa específica obtida foi $500 \mathrm{~kg}$ de forragem $/ \mathrm{m}^{3}$ e, nas de cana-de-açúcar queimada, de $800 \mathrm{~kg}$ de forragem $/ \mathrm{m}^{3}$. Após a compactação da forragem, os silos foram vedados com fita adesiva, pesados e armazenados à temperatura ambiente.

Decorrido o tempo previsto 1, 4, 7, 14, 28 e 56 dias de armazenamento em anaerobiose, os silos foram novamente pesados, para determinação das perdas por gases. Após a pesagem, os silos foram abertos, a silagem retirada e o conjunto silo, areia, tela e tecido de náilon foram pesados para quantificação do efluente produzido, conforme descrito por Siqueira et al. (2007a).

Antes da ensilagem e após a aplicação do inoculante, a forragem foi amostrada três vezes para cada tratamento e dividida em três subamostras: a primeira foi pesada e levada para estufa de ventilação forçada a $60^{\circ} \mathrm{C}$ durante 72 horas; a segunda foi preparada para obtenção do extrato aquoso, segundo metodologia descrita por Kung Junior et al. (1984); e a terceira para as determinações microbiológicas. $\mathrm{Na}$ abertura após homogeneização da silagem, retiraram-se três subamostras de cada silo, que foram preparadas conforme metodologia descrita para as amostras coletadas antes da ensilagem. As amostras levadas para estufa foram novamente pesadas, moídas em moinho de faca até as partículas atingirem menos de $1 \mathrm{~mm}$ e armazenadas em potes de plástico, para posterior determinação dos teores de matéria seca (MS) e proteína bruta (PB), segundo AOAC (1990). A digestibilidade verdadeira in vitro da matéria seca (DIVMS) foi determinada segundo Robertson \& Van Soest (1981). Os teores de fibra em detergente neutro (FDN) e fibra em detergente ácido (FDA) foram avaliados pelo método sequencial segundo técnicas descritas por Robertson \& Van Soest (1981), com as amostras submetidas à digestão em solução detergente por $40 \mathrm{~min}$ em autoclave a $111^{\circ} \mathrm{C}$ e $0,5 \mathrm{~atm}$ (Deschamps, 1999).

Determinou-se a recuperação da matéria seca digestível verdadeira descrita por Siqueira et al. (2007b) como a relação entre a quantidade de matéria seca digestível verdadeira na abertura e quando ensilada, um parâmetro que relaciona perdas quantitativas e qualitativas. 
O extrato aquoso obtido foi utilizado para determinação do $\mathrm{pH}$ com o uso de potenciômetro digital, do ácido acético e do etanol, segundo metodologias descritas por Souza et al. (2008).

As análises microbiológicas foram realizadas no Laboratório de Microbiologia da FCAV/Unesp em todos os tempos de abertura dos silos. Para tanto, foram pesados $25 \mathrm{~g}$ de silagem e adicionado a $225 \mathrm{~mL}$ de água peptonada a $0,1 \%$. Foram realizadas diluições de $10^{-1}$ a $10^{-5} \mathrm{e}$, a partir dessas diluições, foram realizadas as semeaduras em placas de Petri contendo meio de cultivo adequado para cada grupo de microrganismos. Para contagem de leveduras, utilizou-se batata dextrose ágar batata (Difco) acidificado a pH de 3,5 e logo depois incubadas em aerobiose por 72 horas, quando, então, foi feita a contagem das colônias. A contagem total de Lactobacillus foi realizada conforme metodologia descrita por Jonsson (1991), e adaptada por Jobim et al. (1999), as placas foram incubadas a $35{ }^{\circ} \mathrm{C}$ em jarras de anaerobiose.

Os dados foram analisados pelo PROC REG do programa estatístico SAS (SAS, 1999). As equações foram escolhidas com base nos seus coeficientes de determinação e na significância dos coeficientes de regressão utilizando-se o teste t. Não encontrando equações significativas, aplicou-se a análise de variância pelo procedimento PROC GLM e as médias foram avaliadas pelo LSMEANS a 5\%.

\section{Resultados e Discussão}

Durante o período de armazenamento, os teores de MS reduziram em todos os tratamentos. Comparando-se o teor de MS na ensilagem (34,07\%) com os valores após 56 dias de armazenamento (23,95\%), observa-se redução de 10 pontos percentuais (Figura 1). As reduções de maiores magnitudes ocorreram logo no primeiro dia de armazenagem (Tabela 1), possivelmente em função da alta capacidade fermentativa da cana-de-açúcar. Todavia, observou-se queda nos teores de MS até sete dias de armazenagem, com posterior estabilização até o dia 56. As silagens de cana-deaçúcar queimada na média reduziram duas unidades percentuais a mais que as de cana-de-açúcar in natura, porém essa alteração foi devido à queda nos teores de MS das silagens de cana-de-açúcar queimada sem inoculante, pois a queimada com inoculante não diferenciou das silagens de cana-de-açúcar in natura.

Nas silagens de cana-de-açúcar queimada, o L. buchneri reduziu a queda nos teores de MS, enquanto, nas silagens de cana-de-açúcar in natura, este efeito não foi constatado.
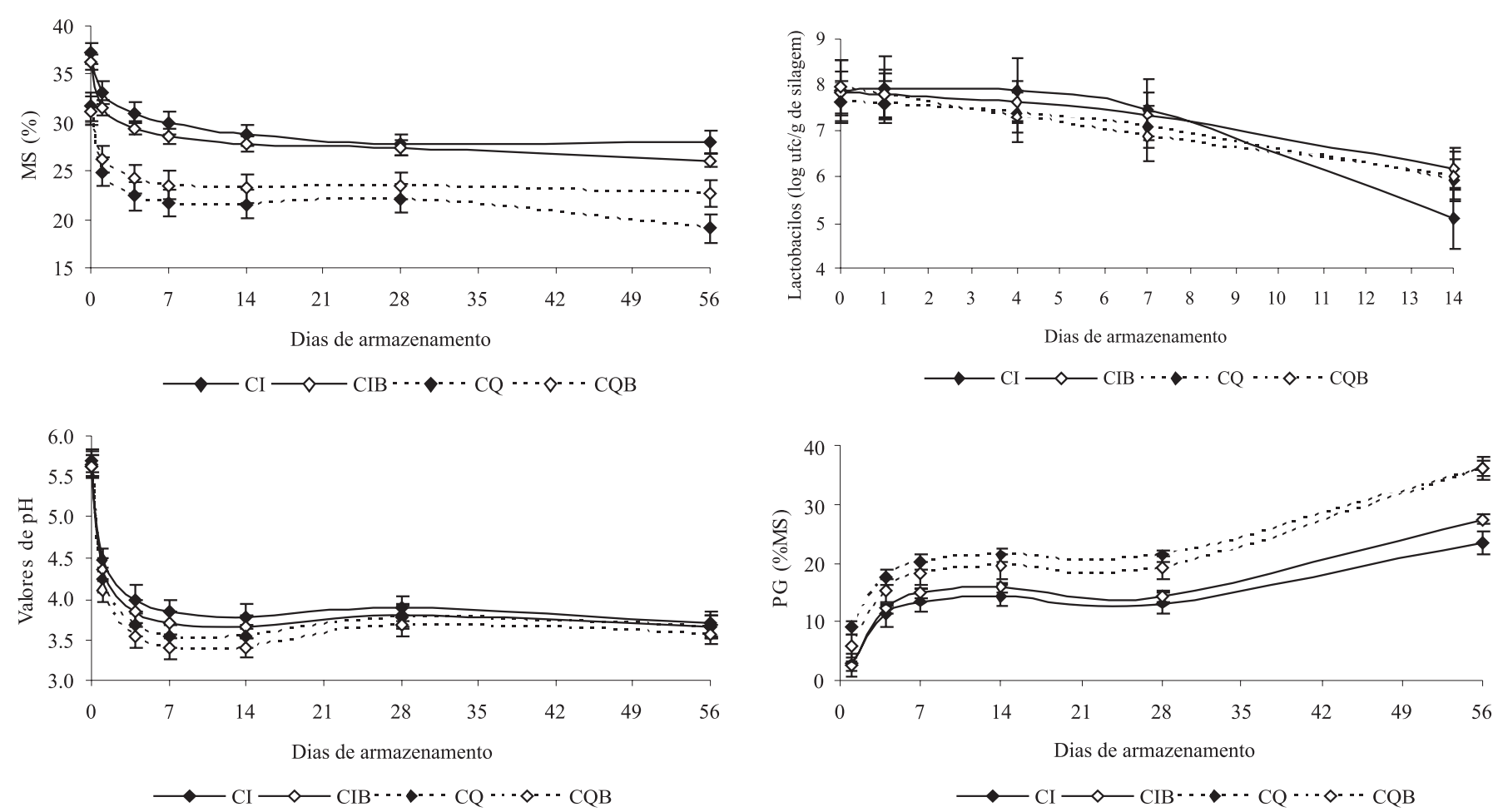

CI = silagem de cana-de-açúcar in natura sem aditivo; CIB = silagem de cana-de-açúcar in natura tratada com $L$. buchneri; CQ = silagem de cana-de-açúcar queimada sem aditivo; CQB = silagem de cana-de-açúcar queimada tratada com L. buchneri.

Figura 1 - Variação temporal dos teores de matéria seca (MS), da população de lactobacilos, valores de pH e perdas por gases (PG) durante o armazenamento de silagens de cana-de-açúcar, in natura ou queimada, e tratadas ou não com L. buchneri. 


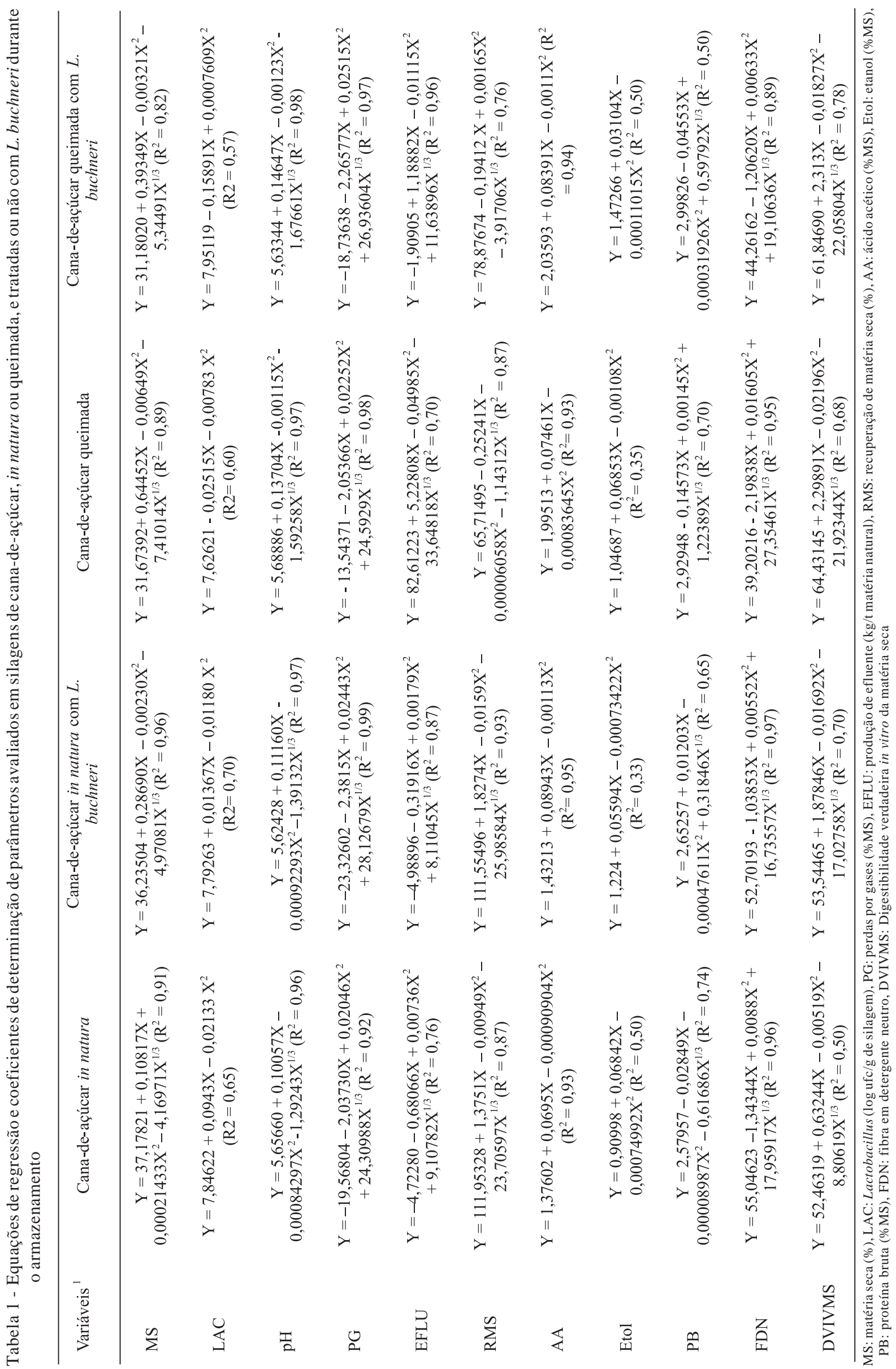


Teoricamente, esse efeito estaria associado ao controle da população de leveduras, devido à produção de ácido acético pelo L. buchneri, todavia, não foram observados, neste estudo nenhum desses efeitos (Tabela 2; Figura 2). Desta forma, pode-se relacionar a redução na queda dos teores de MS à menor perda por efluente (Figura 2). Siqueira et al. (2010) também observaram efeito do L. buchneri em reduzir a queda dos teores de MS de silagens de cana-de-açúcar queimada. Todavia, esses autores também comentam que não há uma explicação na literatura que elucide esse fato.

Não foram obtidas equações que ajustassem para avaliar o comportamento da população de leveduras, no entanto, foram significativas as interações entre dias $\times$ manejo e dias $\times$ aditivos (Tabela 2). Apenas antes da ensilagem foi constatada diferença significativa na população de leveduras entre cana-de-açúcar in natura e queimada 4,85 e 5,43 log ufc/g de forragem, respectivamente. Bernardes et al. (2007) justificaram que, após a queima, pode haver recontaminação da cana-de-açúcar por leveduras, devido à exudação de conteúdo celular (açúcares) pelas rachaduras do colmo, provocadas pelas altas temperaturas do fogo.

Em ambas as formas de manejo, as maiores populações de leveduras foram observadas no primeiro dia de armazenamento. Todavia, nas silagens de cana-de-açúcar queimada, o primeiro dia não foi significativamente diferente do sétimo dia $(\mathrm{P}>0,05)$. Após o sétimo dia de armazenamento, não se constatou população superior a $2 \mathrm{log} \mathrm{ufc} / \mathrm{g}$ de silagem. No trabalho de Pedroso et al. (2005), foi constatada redução de leveduras para valores inferiores a 2 log ufc/g de silagem após 45 dias de armazenamento, porém a avaliação anterior foi realizada aos 15 dias, consequentemente a redução da contagem de leveduras pode ter ocorrido logo após essa avaliação.

Esperava-se efeito do L. buchneri na redução na população de leveduras nas silagens de cana-de-açúcar, tanto in natura quanto queimada. Vários autores observaram efeito significativo do L. buchneri na redução das perdas de matéria seca e esses atribuíram ao possível controle da população de leveduras (Pedroso et al., 2005; Siqueira et al., 2007a; Siqueira et al., 2010; Schmidt et al., 2007). A explicação para o controle da população de leveduras pelo L. buchneri está fundamentada na elevação da concentração de ácido acético (Oude Elferink, 2001), que, segundo Moon (1983), é um composto capaz de inibir o crescimento de leveduras.

Kleinschmit \& Kung Junior (2006) avaliaram a utilização do L. buchneri com o objetivo de controlar a população de leveduras e mofos em silagens de milho, sorgo, gramíneas e de grãos úmidos durante a fase de aerobiose. Os autores realizaram uma avaliação de 23 estudos por meio da metaanálise e concluíram que doses do inóculo inferiores a $1 \times 10^{5} \mathrm{ufc/g}$ de silagem não foram efetivas em controlar o crescimento de fungos (leveduras e fungos filamentosos). Neste estudo foi utilizada a dose de $5 \times 10^{4} \mathrm{ufc} / \mathrm{g}$ de massa ensilada, que é a dose recomendada pelo fabricante deste aditivo no Brasil e representa metade da dose considerada como limiar entre dose baixa e alta $\left(1 \times 10^{5} \mathrm{ufc} / \mathrm{g}\right.$ de massa ensilada). Dos 23 estudos analisados, apenas em cinco foram aplicadas concentrações inferiores a $1 \times 10^{5} \mathrm{ufc} / \mathrm{g}$ de massa ensilada. A maior frequência está entre as doses de $5 \times 10^{5}$ a $1 \times 10^{6}$ ufc/g de massa ensilada, que representam 10 a 20 vezes a dose estudada nesse trabalho, respectivamente. A dose utilizada pode ser uma das possíveis explicações para a ausência de resultados positivos da ação do L. buchneri nas silagens estudadas. Outra explicação pode ser a presença de elevada população epífita de leveduras (Tabela 2) e outros microrganismos epífitos na cana-de-açúcar no momento da ensilagem, que podem competir por substrato com o L. buchneri reduzindo sua chance de atuação eficiente.

O L. buchneri foi adaptado por Nussio \& Schmidt (2004) como um possível aditivo a ser utilizado com sucesso na ensilagem da cana-de-açúcar, devido aos resultados obtidos nas pesquisas até o presente momento. Schmidt (2008) aponta que $L$. buchneri foi o aditivo mais pesquisado na

Tabela 2 - Variação temporal da população de leveduras (log ufc/g de silagem) durante o armazenamento de silagens de cana-de-açúcar, in natura ou queimada, e tratadas ou não com L. buchneri

\begin{tabular}{|c|c|c|c|c|c|c|c|}
\hline \multirow[t]{2}{*}{ Fator } & \multicolumn{7}{|c|}{ Dias de armazenamento } \\
\hline & 0 & 1 & 4 & 7 & 14 & 28 & 56 \\
\hline \multicolumn{8}{|l|}{ Manejo } \\
\hline in natura & $4,85 \mathrm{BC}$ & $6,44 \mathrm{Aa}$ & $5,11 \mathrm{Ac}$ & $5,61 \mathrm{Ab}$ & $\mathrm{ND}^{1}$ & ND & ND \\
\hline Queimada & $5,43 \mathrm{Ab}$ & $6,02 \mathrm{Aa}$ & $4,84 \mathrm{Ac}$ & 5,57 Aab & ND & ND & ND \\
\hline \multicolumn{8}{|l|}{ Aditivos } \\
\hline Sem L. buchneri & $5,33 \mathrm{Ab}$ & $6,21 \mathrm{Aa}$ & $5,45 \mathrm{Ab}$ & 5,73Aab & ND & ND & ND \\
\hline Com L. buchneri & $4,96 \mathrm{Ac}$ & $6,25 \mathrm{Aa}$ & $4,49 B \mathrm{c}$ & $5,44 \mathrm{Ab}$ & ND & ND & ND \\
\hline CV (\%) & & & & & & & 7,59 \\
\hline
\end{tabular}

Médias seguidas da mesma letra, maiúscula na coluna e minúscula na linha dentro de cada interação, não diferiram estatisticamente pelo LSMEANS (P>0,05). ND = não-determinado (contagem menor que 2 log ufc/g de silagem). 
ensilagem da cana-de-açúcar (25 trabalhos), principalmente pelos bons resultados obtidos por Pedroso et al. (2006), dados divulgados por Pedroso (2003). Schmidt (2008) relatou que a variabilidade no padrão de resposta do L. buchneri parece ser superior à assistida para outros aditivos (ureia, óxido de cálcio, benzoato de sódio), por se tratar de um organismo vivo. Assim, depende de uma série de fatores, como substrato, umidade e população inicial, entre outros.

A população inicial pode ser um das principais justificativas para a falta de efeito de um inoculante bacteriano. Uma constatação da importância do aumento da dose foi obtida por Sousa et al. (2008), que utilizaram na ensilagem da cana-de-açúcar o L. buchneri na dose de $3,64 \times 10^{5}$ ufc/g de massa ensilada e também a associação do L. buchneri com o Pedioccocus pentosassus na dose de $1 \times 10^{6} \mathrm{ufc} / \mathrm{g}$ de massa ensilada. Neste caso, que as silagens tratadas com a combinação de um aditivo homo e heterolático (L. buchneri), porém em doses mais altas e normalmente preconizadas no exterior, apresentaram resultados mais favoráveis que as silagens tratadas apenas com L. buchneri em dose baixa, maiores teores de ácido acético 9,26 versus $6,12 \%$ da MS, menores teores de etanol 1,30 versus $11,53 \%$ da MS e consequentemente maior recuperação da matéria seca 79,7 versus $66,6 \%$.

Observou-se presença de Lactobacillus em contagem acima de $2 \log$ ufc/g silagem até o 14음ia (Figura 1). Não foi observada diferença entre as silagens em nenhum dos tempos de armazenagem. Em relação aos dias de armazenagem, reduções significativas ocorreram apenas no $14^{\circ}$ dia.

Esperava-se que, com a inclusão do L. buchneri na ensilagem de cana-de-açúcar, a população de lactobacilos aumentasse, pois os microrganismos adicionados pertencem a esse gênero. No entanto, a dose utilizada, pode não ter sido suficiente para estabelecer competição entre o microrganismo do inoculante e a microflora epífita. A inoculação utilizada foi de $5 \times 10^{4} \mathrm{ufc/g}$ de massa ensilada e a microflora epífita de lactobacilos média foram de aproximadamente de $1 \times 10^{7}$ ufc/g de massa ensilada, o que significa dizer que a população epífita de lactobacilos foi 200 vezes a quantidade da população inoculada.

Em relação aos tratamentos, constataram-se menores valores de $\mathrm{pH}$ nas silagens de cana-de-açúcar queimada no período de 4 a 14 dias de armazenamento (Figura 1). A redução mais rápida dos valores de $\mathrm{pH}$ pode ser atribuída às maiores concentrações de açúcares solúveis. Já Bernardes et al. (2007) observaram que silagens de cana-de-açúcar queimada apresentaram valores de $\mathrm{pH}(3,7)$ superiores aos daquelas produzidas com cana-de-açúcar in natura $(3,5)$, porém com diferença de pequena magnitude.
Os valores de pH já se encontravam estáveis após o quarto dia de armazenagem em todos os tratamentos (Figura 1). Evangelista et al. (2009) também observaram redução dos valores de $\mathrm{pH}$ para 3,63 com quatro dias de fermentação. O rápido decréscimo do $\mathrm{pH}$ pode ser atribuído ao alto teor de carboidratos solúveis (Pedroso et al., 2005) e à baixa capacidade tampão (Siqueira et al., 2007a; Evangelista et al., 2009), o que assegura bons parâmetros em termos de qualidade sanitária. Valores de $\mathrm{pH}$ inferiores a 3,7 a partir do décimo quarto dia justificam as baixas contagens dos Lactobacillus em tempos de fermentação mais prolongados (Figura 1). Segundo McDonald et al. (1991), as bactérias ácido lático possuem distintas formas de tolerância à acidez, e as mais resistentes apresentam crescimento até o $\mathrm{pH}$ de 3,5. Segundo esses autores, as bactérias acidoláticas normalmente mantêm o diferencial de pH usando $\mathrm{H}^{+}$ATPase, mas eventualmente acumulam ácidos produtos da fermentação e consequentemente reduzem o pH interno, resultando em interrupção do metabolismo e crescimento do microrganismo.

$\mathrm{Na}$ maioria dos estudos, seja com cana-de-açúcar (Siqueira et al. 2007a; Schmidt et al., 2007) seja na ensilagem de outras culturas como milho (Ranjit et al., 2002) e sorgo (Filya, 2003), as silagens com L. buchneri normalmente apresentaram valores de $\mathrm{pH}$ superiores às silagens não tratadas. Uma das possíveis causas são os menores teores de ácido lático observados nas silagens inoculadas (Kleinschmit \& Kung Junior, 2006). O L. buchneri, além de ocasionar fermentação heterolática (McDonald et al., 1991), produzindo maiores quantidade de ácido acético que bactérias homoláticas (Weinberg \& Muck, 1996), pode converter o ácido lático em ácido acético (Oude Elferink et al., 2001). Como o ácido lático possui um $\mathrm{pK}_{\mathrm{a}}$ baixo $(3,86)$, torna-se o principal responsável pela redução dos valores de $\mathrm{pH}$ na ensilagem. No entanto, a ausência de valores de $\mathrm{pH}$ mais altos nas silagens inoculadas, neste estudo, pode ser atribuída à falta de atuação consistente do aditivo nessas condições.

Os dados de perdas por gases das quatro silagens estudadas em função do tempo de fermentação apresentaram comportamentos semelhantes, porém com valores distintos. No entanto, as silagens de cana-de-açúcar queimada apresentaram maiores perdas por gases em comparação às de cana-de-açúcar in natura. Observou-se aumento das perdas por gases até o sétimo dia, estabilização até o $28^{\circ}$ dia e novamente elevação até o 56ํㅜ dia. A utilização do L. buchneri não interferiu sobre esse parâmetro, à exceção das silagens de cana-de-açúcar in natura com 56 dias (Figura 1). 
A perda por gases está diretamente relacionada à ação de microrganismos sobre a massa ensilada. No caso específico da cana-de-açúcar, esses microrganismos seriam as leveduras. Segundo McDonald et al. (1991), a fermentação por leveduras gera $\mathrm{CO}_{2}$, que durante o período de armazenagem, é perdido na forma de gases. Contudo, não se observou presença de leveduras e de lactobacilos superiores a 2 log ufc/g de silagem após o dia 7 e 14, respectivamente (Tabela 2; Figura 1). Dessa forma, não se justifica o aumento das perdas ocorridas no período final de avaliação do dia 28 ao 56. No entanto, Santos et al. (2008), em revisão sobre microbiologia de forragens conservadas, discutiram sobre a limitação dos métodos de quantificação de microrganismos convencionais atualmente utilizados (meio seletivo de cultura de microrganismo), pois grande parte dos microrganismos é refratária aos meios de culturas. Segundo Giraffa (2004) os métodos clássicos de plaqueamento permitem apenas a caracterização superficial de grupos de microrganismos. Dessa forma, pode-se afirmar que nas silagens de canade-açúcar estudadas outros microrganismos que não foram quantificados pelas técnicas utilizadas poderiam ter atuado na massa ensilada gerando perda por gases no período supracitado. Ou o meio de cultura utilizado para determinação da população de leveduras não foi eficiente em permitir o crescimento dos microrganismos.

Em relação à queima, Siqueira et al. (2009) não observaram diferença significativa nas perdas por gases entre silagens de cana-de-açúcar in natura ou queimada tratadas com diferentes aditivos químicos ou bacterianos, inclusive com o L. buchneri. Bernardes et al. (2007), no entanto, não avaliaram a perda por gases, mas observaram maiores concentrações de etanol e maior população de leveduras nas silagens de cana-de-açúcar queimada, esses parâmetros são um indício de maiores perdas por gases, pois segundo Pedroso et al. (2005) existe alta correlação $(0,90)$ entre perda por gases e concentração de etanol.

A possível potencialização da perda por gases nas silagens de cana-de-açúcar queimada pode ser atribuída à maior concentração de açúcares nessas silagens, devido à retirada da palha, e também à quebra de sacarose em glicose mais frutose, que são açúcares simples. Segundo McDonald et al. (1991), glicose e frutose possuem taxas de fermentação no silo por leveduras e pela maioria dos microrganismos heteroláticos superiores à da sacarose, podendo gerar maiores quantidades de $\mathrm{CO}_{2}$.

As silagens de cana-de-açúcar queimada apresentaram maiores produções de efluentes (Figura 2). Atribui-se a maior produção de efluente à retirada da palha, que poderia atuar como aditivo sequestrante de umidade, reduzindo a produção de efluentes. Siqueira et al. (2010) também observaram aumento significativo da produção de efluente em $30 \mathrm{~kg} / \mathrm{t}$ de forragem fresca nas silagens de cana-deaçúcar queimada em relação às produzidas com cana-deaçúcar in natura. Outro fato que tem importância sobre a produção de efluentes é a massa específica. Nas silagens de cana-de-açúcar in natura, a massa específica obtida foi de $500 \mathrm{~kg} / \mathrm{m}^{3}$, enquanto nas silagens de cana-de-açúcar queimada o valor foi de $800 \mathrm{~kg} / \mathrm{m}^{3}$. Tavares et al. (2009) observaram aumento na produção de efluente na ensilagem do capim-tanzânia de 50 para aproximadamente 200 L/t matéria verde com o aumento da massa específica de 400 para $900 \mathrm{~kg} / \mathrm{m}^{3}$. Dessa forma, pode-se atribuir o aumento na produção de efluentes a dois fatores: eliminação da palha pelo fogo e aumento na massa específica da silagem.

Nas silagens de cana in natura, não foi observado efeito positivo do aditivo, porém, nas silagens de cana queimada, a inclusão do aditivo propiciou menor produção do efluente em todos os tempos de armazenagem (Figura 2). Schmidt (2008) verificou que, em 23\% dos trabalhos que utilizaram o L. buchneri, foi constatada a redução da produção de efluentes. Em termos médios, conforme os dados levantados por Schmidt (2008), os valores observados neste trabalho encontram-se dentro da variação observada nas compilação de dados da literatura, que é de 6 a $95,9 \mathrm{~kg} / \mathrm{t}$ de forragem fresca.

As silagens de cana-de-açúcar in natura apresentaram maiores recuperações de MS em comparação às de canade-açúcar queimada durante todo o período de avaliação (Figura 2). Siqueira et al. (2010) também constataram maiores recuperações de MS nas silagens de cana-de-açúcar in natura em média 4 unidades percentuais. A queima propicia maior disponibilidade de açúcares simples (glicose + frutose) e também promove aumento proporcional dos açúcares, devido à eliminação da palha. A abundância de substratos é um dos principais controladores do crescimento microbiano. Nesse sentido, esperava-se que houvesse maiores populações de leveduras e de lactobacilos nas silagens de cana-de-açúcar queimada, o que não ocorreu (Tabela 2; Figura 1). Entretanto, a massa especifica foi muito maior (800 kg/m3), assim a concentração de oxigênio no meio foi menor, e isso pode influenciar no crescimento de microrganismos, principalmente na fase de fermentação.

As recuperações de matéria seca condizem com os dados observados nas perdas de gases (Figura 1) e com a produção de efluentes (Figura 2). Além da explicação sobre a baixa eficiência das metodologias de plaqueamento na quantificação dos microrganismos, outra justificativa para 

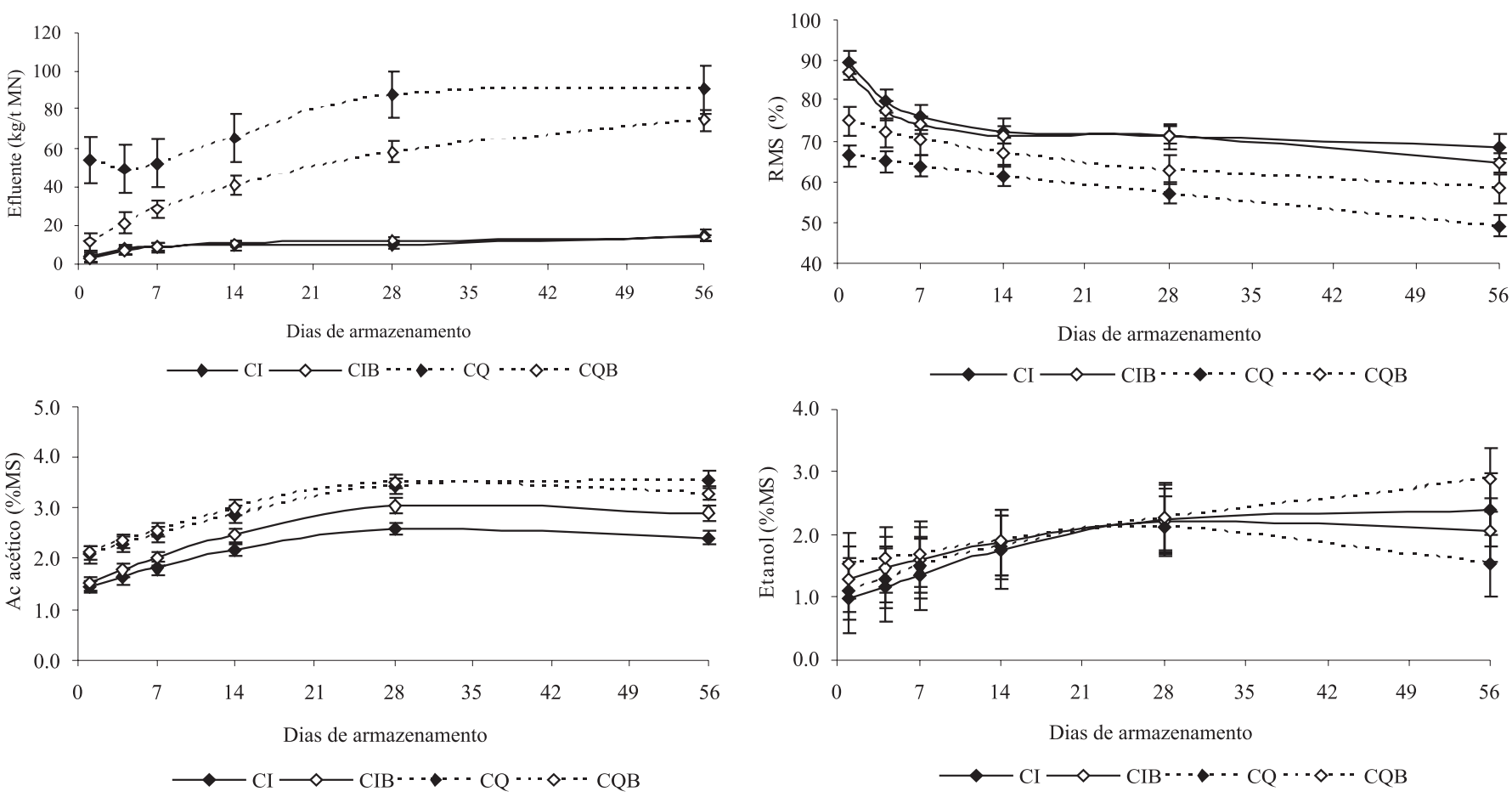

CI = silagem de cana-de-açúcar in natura sem aditivo; CIB = silagem de cana-de-açúcar in natura tratada com $L$. buchneri; CQ = silagem de cana-de-açúcar queimada sem aditivo; CQB = silagem de cana-de-açúcar queimada tratada com L. buchneri.

Figura 2 - Variação temporal da produção de efluentes, recuperação de matéria seca (RMS), concentração de ácido acético e de etanol durante o armazenamento de silagens de cana-de-açúcar, in natura ou queimada, e tratadas ou não com L. buchneri.

as menores perdas seria a maior concentração de ácido acético nas silagens de cana-de-açúcar queimada (Figura 2). Microrganismos heterofermentativos produzem além de ácidos, $\mathrm{CO}_{2}$ que pode ser perdido na forma de gases e consequentemente reduziram a recuperação da MS.

$\mathrm{O}$ aditivo teve efeito apenas nas silagens de cana-deaçúcar queimada e esse resultado está relacionado aos maiores teores de MS (Figura 1) e à redução na produção de efluente (Figura 2) nas silagens de cana-de-açúcar queimada inoculada com L. buchneri. Os demais parâmetros, que poderiam ser melhorados com a utilização do L. buchneri, e que afetariam a recuperação de MS seriam a redução da população de leveduras (Tabela 2), as perdas por gases e a concentração de etanol (Figura 1), no entanto não foi observado efeito positivo em nenhum desses parâmetros.

No decorrer do tempo de fermentação, ocorreu redução da recuperação de matéria seca (Figura 2), e as perdas se prolongaram até o dia 56. Pedroso et al. (2005) observaram redução das recuperações de MS até 45 dias de fermentação, tendo como menor valor $70 \%$ de recuperação de MS. No presente estudo, foram observadas recuperações de matéria seca de até $47 \%$.

Houve maior concentração de ácido acético nas silagens de cana-de-açúcar queimada, se comparadas às de cana-deaçúcar in natura, em todos os tempos avaliados (Figura 2).
Mesmo não havendo diferença na contagem de lactobacilos, pode-se inferir que os microrganismos heteroláticos tiveram maior eficiência de atuação nessas silagens, propiciando elevação na concentração de ácido acético, sem provocar aumento da população.

A concentração de ácido acético aumentou em todas as silagens até 28 dias de armazenamento, permanecendo estável até o dia 56 (Figura 2). Ávila et al. (2009) avaliaram silagens de cana-de-açúcar inoculadas com cepas de $L$. buchneri e observaram que o pico de concentração do ácido acético ocorreu aos 30 dias de fermentação e que após este tempo houve redução na concentração desse composto, até 90 dias de fermentação. Contudo, em outras culturas como o capim-marandu e capim-tanzânia (Coan et al., 2007), milho (Nishino et al., 2003) também foram observadas elevações do ácido acético em períodos de fermentação de até 56 dias.

Kleinschmit \& Kung Júnior (2006) observaram que a utilização do L. buchneri elevou a concentração do ácido acético em silagens de milho em $21 \%$ quando a dose utilizada foi inferior a $1 \times 10^{5} \mathrm{ufc/g}$ de massa ensilada, já nas doses superiores a essa a concentração foi aumentada em 78\%.

Nas silagens de cana-de-açúcar in natura houve diferença significativa na concentração de ácido acético entre as silagens tratadas ou não com $L$. buchneri a partir 
do dia 14. No entanto, essa diferença não foi eficiente em controlar o crescimento de leveduras (Tabela 2) nem elevar a recuperação de matéria seca (Figura 2). Nas silagens de cana-de-açúcar queimada não se observou diferença entre as silagens inoculadas e as controle. Schmidt et al. (2007), avaliando silagens tratadas ou não com L. buchneri não constataram diferenças significativas na concentração de ácido acético.

Em relação à concentração de etanol, não houve diferença, entre os tratamentos, provavelmente devido à alta dispersão dos dados obtidos, que pode ser constatada pela proporcionalidade dos desvios-padrão, em relação aos valores absolutos da variável em questão. A concentração de etanol aumentou até o dia 28 com estabilização até o dia 56 (Figura 2).

Schmidt (2008) avaliou 16 estudos que compararam a utilização do $L$. buchneri na ensilagem da cana-de-açúcar, sendo que em $50 \%$ foi observada redução da concentração de etanol. Um dos principais efeitos esperados com a utilização do L. buchneri em silagens de cana-de-açúcar seria a redução da concentração do etanol, sendo que está estaria relacionada com o controle da população de leveduras. Ressalta-se que, conforme exposto por Kleinschmit \& Kung Júnior (2006), a dose de L. buchneri utilizada não tenha sido suficiente para ter controle efetivo sobre a população destes microrganismos.

O valor máximo de PB foi obtido aos 28 dias de armazenamento, nas silagens de cana-de-açúcar in natura (3,58\%) e nas de cana-de-açúcar queimada e tratadas com L. buchneri (3,79\%) (Figura 3). Já nas silagens de cana-deaçúcar queimada sem $L$. buchneri os maiores valores foram obtidos aos sete dias (4,32\%). A elevação da PB ocorreu devido ao consumo de carboidratos solúveis. Pode-se inferir que, nas silagens de cana-de-açúcar queimada, com o prolongar do tempo de armazenamento até 56 dias, houve maiores perdas. Também não houve efeito do L. buchneri sobre os teores de PB (Figura 3).

Não se observou diferença entre as silagens tratadas ou não com L. buchneri. Esperava-se que nas silagens tratadas ocorresse menor elevação dos teores de FDN, devido ao possível controle sobre a ação das leveduras. Uma possível explicação para inobservância do efeito deste inoculante, pode estar na dose utilizada (Figura 3). A retirada da palha reduziu o conteúdo de FDN no momento da
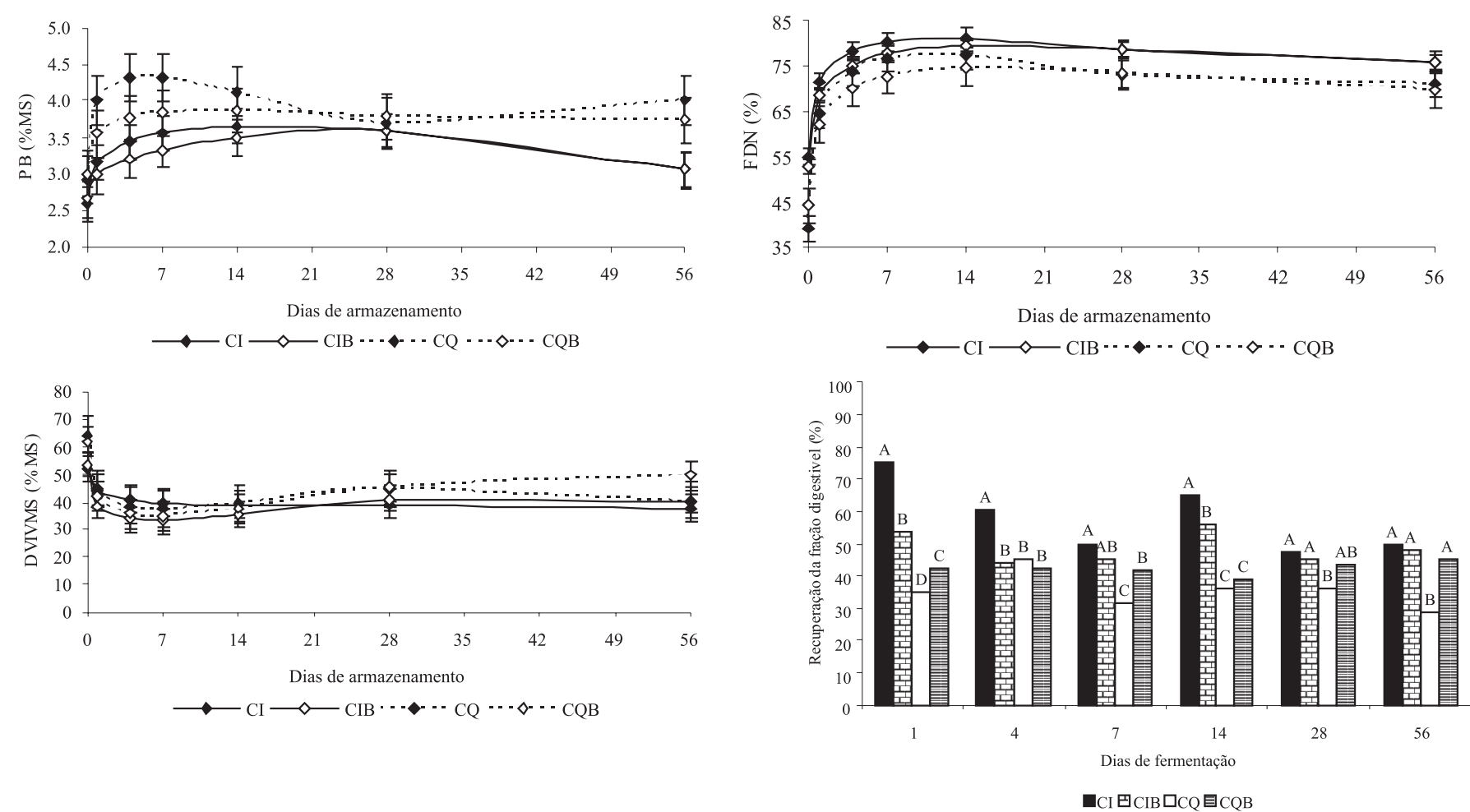

CI = silagem de cana-de-açúcar in natura sem aditivo; CIB = silagem de cana-de-açúcar in natura tratada com $L$. buchneri; CQ = silagem de cana-de-açúcar queimada sem aditivo; CQB = silagem de cana-de-açúcar queimada tratada com L. buchneri. Barras com a mesma letra, dentro de cada dia de armazenamento, não diferiram estatisticamente pelo teste Tukey $(\mathrm{P}<0,05)$.

Figura 3 - Variação temporal durante o armazenamento dos teores de proteína bruta (\%MS), fibra em detergente neutro, digestibilidade verdadeira in vitro da matéria seca (\%MS) e recuperação da matéria seca digestível de silagens de cana-de-açúcar, in natura ou queimada, e tratadas ou não com L. buchneri. 
ensilagem. A diferença média no momento da ensilagem foi de 14 unidades percentuais e foi reduzida para 6 com 56 dias de armazenamento. A redução da diferença pode ser atribuída a maiores perdas de MS nas silagens de cana-de-açúcar queimada e efluentes que podem carrear compostos solúveis e assim aumentar proporcionalmente os teores de FDN.

Os teores de FDN elevaram-se acentuadamente em todas as silagens até o sétimo dia de armazenamento. Houve tendência de queda de 14 até o 56 dias de armazenamento (Figura 3). As leveduras dominam o processo fermentativo em silagens de cana-de-açúcar, em que, na maioria das vezes, não são inibidas pela redução do pH e possuem a habilidade de crescer em intervalos de $\mathrm{pH}$ de 2 a 8. No caso das leveduras, a fermentação vai produzir etanol, gás carbônico, água e ATP, gerando perdas de MS e consequentemente, propiciando aumentos proporcionais das frações fibrosas. Evangelista et al. (2009), avaliando o perfil de fermentação de silagens de cana-de-açúcar também constataram elevação dos teores de FDN de 55\% no momento da ensilagem até $75 \%$ com 50 dias de armazenamento. A elevação foi atribuída ao consumo de carboidratos solúveis por leveduras. Bernardes et al. (2007) relatam que a maioria dos fungos e das leveduras necessita de oxigênio para seu crescimento. Todavia, algumas espécies de leveduras mantém seu metabolismo ativo mesmo em condições de anaerobiose fermentando os açúcares (Walker, 1998).

A digestibilidade verdadeira in vitro da matéria seca (DVIVMS), da cana-de-açúcar in natura foi inferior a da cana-de-açúcar queimada, no momento da ensilagem (Figura 3), provavelmente pela eliminação da palha, que é um constituinte rico em frações fibrosas e de baixa digestibilidade. Ao longo dos dias de armazenamento observou por diversas vezes a equivalência da DVIVMS entre as silagens, ou a alternância entre a superioridade de um tratamento em relação ao outro. O principal fato é a severa redução da DVIVMS já no primeiro dia de armazenamento (Figura 3), que chega a representar cerca de 20 unidades percentuais aos 56 dias de armazenamento. A redução da digestibilidade foi observada por diversos autores (Balieiro Neto et al., 2007; Siqueira et al., 2007b; Pedroso et al., 2007; Sousa et al., 2008), no entanto, a queda observada neste trabalho foi a maior de todos os artigos revisados. A redução acentuada da digestibilidade corrobora com os dados de recuperação de matéria seca (Figura 2) e perdas por gases (Figura 1).

Outra forma de visualizar os efeitos da ensilagem sobre as perdas quantitativas e as alterações nutritivas da canade-açúcar é pela determinação da recuperação da matéria seca digestível, preconizado por Siqueira et al. (2007b) (Figura 3). Ao avaliar os tempos de armazenamento de 14,
28 e 56 dias, que são factíveis de serem utilizados como tempo inicial de utilização de um silo em uma propriedade agrícola, pode-se inferir que nas silagens de cana-de-açúcar in natura a recuperação de MS digestível reduziu após 14 dias de armazenamento. Já as silagens de cana-deaçúcar queimada apresentavam elevada magnitude de perda mesmo aos 14 dias. Isto equivale a dizer que em silagens de cana-de-açúcar tem-se que buscar aditivos que controlem a ação de leveduras, que muita das vezes podem ser desconhecidas e não quantificadas pelos métodos de avaliação normalmente utilizados (Santos et al. 2008). A indicação simplista de utilização rápida da silagem de canade-açúcar não é efetiva, pois as principais perdas ocorrem nos primeiros dias de estocagem.

Mesmo havendo, toda uma ação teórica da atuação do L. buchneri e alguns bons resultados com sua utilização na ensilagem da cana-de-açúcar, ocorrem muitas variações nas repostas conforme foi observado neste estudo. Uma possível solução seria o aumento da dose utilizada, que com base nos resultados obtidos em trabalhos internacionais, deveria ser de aproximadamente $5 \times 10^{5} \mathrm{ufc} / \mathrm{g}$ de massa ensilada, ou seja, dez vezes a dose utilizada no Brasil. Estudos para a comprovação e validação da dose adequada devem ser realizados.

\section{Conclusões}

Silagens de cana-de-açúcar queimada apresentam maiores perdas e alterações fermentativas e nutricionais que as silagens de cana-de-açúcar in natura. O aditivo $L$. buchneri deve ser utilizado em silagens de cana-deaçúcar queimada, mas em silagens de cana-de-açúcar in natura seu uso é dispensável.

\section{Referências}

ASSOCIATION OF OFFICIAL ANALYTICAL CHEMISTS - AOAC. Official methods of analysis of the Association of Analytical Chemists. 15.ed. Arlington: 1990. 1117p.

ÁVILA, C.L.S.; PINTO, J.C.; FIGUEIREDO, H.C.P. et al. Effects of na indigenous and a commercial Lactobacillus buchneri strain on quality of sugar cane silage. Grass and Forage Science, v.64, n.4, p.384-394, 2009.

BALIEIRO NETO, G.; SIQUEIRA, G.R.; REIS, R.A. et al. Óxido de cálcio como aditivo na ensilagem de cana-de-açúcar. Revista Brasileira de Zootecnia, v.36, n.5, p.1231-1239, 2007.

BERNARDES, T.F.; REIS, R.A.; SIQUEIRA, G.R. et al. Avaliação da queima e da adição de milho desintegrado com palha e sabugo na ensilagem de cana-de-açúcar. Revista Brasileira de Zootecnia, v.36, n.2, p.269-275, 2007.

COAN, R.M.; REIS, R.A.; GARCIA, G.R. et al. Dinâmica fermentativa e microbiológica de silagens dos capins tanzânia emarandu acrescidas de polpa cítrica peletizada. Revista Brasileira de Zootecnia, v.36, n.5, p.1502-1511, 2007 (supl.). 
DESCHAMPS, F.C. Implicações do período de crescimento na composição química e digestão dos tecidos de cultivares de capim elefante. Revista Brasileira de Zootecnia, v.28, p.1178-1189, 1999.

EVANGELISTA, A.R.; SIQUEIRA, G.R.; LIMA, J.A. et al. Perfil fermentativo de silagens de cana-de-açúcar com e sem inclusão de milho desintegrado com palha e sabugo. Revista Brasileira de Zootecnia, v.38, n.1, p.20-26, 2009.

FILYA, I. The Effect of Lactobacillus buchneri and Lactobacillus plantarum on the fermentation, aerobic stability, and ruminal degradability of low dry matter corn and sorghum silages. Journal of Dairy Science, v.85, n.11, p.3575-3581, 2003.

GIRAFFA, G. Studying the dynamics of microbial populations during food fermentation - a review. FEMS Microbiology Reviews, v.28, n.2, p.251-260, 2004.

JOBIM, C.C.; REIS, R.A.; SCHOCKEN-ITURRINO, R.P. et al. Desenvolvimento de microrganismos durante a utilização de silagens de grãos úmidos de milho e de espigas de milho sem brácteas Acta Scientiarum, v.21, n.3, p.671-676, 1999.

JONSSON, A. Growth of clostridium tyrobutiricum during fermentation and aerobic deterioration of grass silage. Journal Science Food Agriculture, v.54, n.4, p.557-568, 1991.

KLEINSCHMIDT, D.H.; KUNG JUNIOR, L. A meta-analysis of the effects of lactobacillus buchneri on the fermentation and aerobic stability of corn and grass and small-grain silages. Journal of Dairy Science, v.89, n.10, p.4005-4013, 2006.

KUNG JUNIOR, L.; GRIEVE, D.B.; THOMAS, J.W. et al. Added ammonia or microbial inoculant for fermentation and nitrogenous compounds of alfalfa ensiled at various percents of dry matter. Journal of Dairy Science, v.67, n.2, p.299-306, 1984.

McDONALD, P.; HENDERSON, A.R.; HERON, S.J.E. The biochemistry of silage. 2.ed. Marlow: Chalcomb Publications, 1991. 340p.

MOON, N.J. Inhibition of the growth of acid tolerant yeasts by acetate, lactate and propionate and their synergistic mixtures. Journal of Applied Bacteriology, v.55, n.3, p.453-460, 1983.

NISHINO, N.; YOSHIDA, M.; SHIOTA, H. et al. Accumulation of 1,2-propanediol and enhancement of aerobic stability in whole crop maize silage inoculated with Lactobacillus buchneri. Journal of Applied Microbiology, v.94, n.3, p.800-807, 2003.

NUSSIO, L.G.; SCHMIDT, P. Tecnologia de produção e valor alimentício de silagens de cana-de-açúcar. In: SIMPÓSIO SOBRE PRODUÇÃO E UTILIZAÇÃO DE FORRAGENS CONSERVADAS, 2., 2004, Maringá. Anais... Maringá: UEM/CCA/DZO, 2004. p.1-33.

OUDE ELFERINK, S.J.W.H.; KROONEMAN, J.; GOTTSCHAL, J.C. et al. Anaerobic conversion of lactic acid to acetic acid and 1,2-propanediol by Lactobacillus buchneri. Applied and Environmental Microbiology, v.67, n.1, p.125-132, 2001.

PEDROSO, A.F. Aditivos químicos, microbianos no controle de perdas e na qualidade de silagem de cana-de-açúcar (Saccharum officinarum L.). 2003. 120f. Tese (Doutorado em agronomia) - Escola Superior de Agricultura Luiz de Queiroz, Piracicaba.

PEDROSO, A.F.; NUSSIO, L.G.; PAZIANI, S.F. et al. Fermentation and epiphytic microflora dynamics in sugar cane silage. Scientia Agricola, v.62, n.5, p.427-432, 2005.
PEDROSO, A.F.; NUSSIO, L.G.; BARIONI JUNIOR, W. et al. Performance of Holstein heifers fed sugarcane silages treated with urea, sodium benzoate or Lactobacillus buchneri. Pesquisa Agropecuária Brasileira, v.41, n.4, p.649-654, 2006.

PEDROSO, A.F.; NUSSIO, L.G.; LOURES, D.R.S. et al. Efeito do tratamento com aditivos químicos e inoculantes bacterianos nas perdas e na qualidade de silagens de cana-de-açúcar. Revista Brasileira de Zootecnia, v.36, n.3, p.558-564, 2007.

RANJIT, N.K.; TAYLOR; C.C; KUNG, JUNIOR, L. Effect of Lactobacillus buchneri 40788 on the fermentation, aerobic stability and nutritive value of maize silage. Grass and Forage Science, v.57, n.1, p.73-81, 2002.

ROBERTSON, J.B.; VAN SOEST, P.J. The detergent system of analysis and its application to human foods. In: JAMES, W.P.T.; THEANDER, O. (Eds.) The analysis of dietary fiber in food. New York: Marcel Dekker, 1981. p.123-158.

SANTOS, M.C.; QUEIROZ, O.C.M.; NUSSIO, L.G. Microbiologia de forragens conservadas e suas aplicações. In: PRODUÇÃO E UTILIZAÇÃO DE FORRAGENS CONSERVADAS, 2., 2008, Maringá. Anais... Maringá: Masson, 2008. p.101-116.

SCHMIDT, P. Aditivos químicos e biológicos no tratamento de canade-açúcar para alimentação de bovinos. In: JOBIM, C.C.; CECATO, U.; CANTO, M.W. (Eds) Produção e utilização de forragens conservadas. Maringá: Masson, 2008. p.117-152.

SCHMIDT, P.; MARI, L.J.; NUSSIO, L.G. et al. Aditivos químicos e biológicos na ensilagem de cana-de-açúcar. 1. Composição química das silagens, ingestão, digestibilidade e comportamento ingestivo. Revista Brasileira de Zootecnia, v.36, n.5, p.1666-1675, 2007 (supl.).

SIQUEIRA, G.R.; REIS, R.A.; SCHOCKEN-ITURRINO, R.P. et al. Perdas de silagens de cana-de-açúcar tratadas com aditivos químicos e bacterianos. Revista Brasileira de Zootecnia, v.36, n.6, p.2000-2009, 2007a (supl.).

SIQUEIRA, G.R.; REIS, R.A.; SCHOCKEN-ITURRINO, R.P. et al. Associação entre aditivos químicos e bacterianos na ensilagem de cana-de-açúcar. Revista Brasileira de Zootecnia, v.36, n.4, p.789-798, 2007b.

SIQUEIRA, G.R.; REIS, R.A.; SCHOCKENITURRINO, R.P. et al. Queima e aditivos químicos e bacterianos na ensilagem da canade-açúcar. Revista Brasileira de Zootecnia, v.39, n.1, p.103-112, 2010.

SOUSA, D.P.; MATTOS, W.R.S.; NUSSIO, L.G. et al. Efeito de aditivo químico e inoculantes microbianos na fermentação e no controle da produção de álcool em silagens de cana-de-açúcar. Revista Brasileira de Zootecnia, v.37, n.9, p.1564-1572, 2008.

STATISTICAL ANALYSES SYSTEM - SAS. SAS user's guide. Statistics. Version 8.01 Edition. SAS Inst. Cary: 1999. (CD-ROM).

TAVARES, V.B.; PINTO, J.C.; EVANGELISTA, A.R.et al. Efeitos da compactação, da inclusão de aditivo absorvente e do emurchecimento na composição bromatológica de silagens de capim-tanzânia. Revista Brasileira de Zootecnia, v.38, n.1, p.40-49, 2009.

WALKER, G. M. Yeast physiology and biotechnology. London: Wiley Editorial Offices, 1998. 350p.

WEINBERG, Z.G.; MUCK, R.E. New trends and opportunities in the development and use inoculants for silage. FEMS Microbiology Reviews, v.19, n.1, p.53-68, 1996. 